\title{
Experimental infections with Paracoccidioides brasiliensis Obtained from Armadillos: Comparison to Clinical Isolates
}

\author{
Angela Satie Nishikaku', Maria Terezinha S. Peraçoli ${ }^{2}$, Eduardo Bagagli ${ }^{2}$, Maria Fátima Sugizaki ${ }^{2}$ and Alexandrina Sartori $^{2}$ \\ ${ }^{1}$ Department of Immunology, Institute of Biomedical Sciences, University of São Paulo, São Paulo, SP; ${ }^{2}$ Department of Microbiology and \\ Immunology, Institute of Biosciences, São Paulo State University of Botucatu; Botucatu, SP, Brazil
}

\begin{abstract}
Paracoccidioides brasiliensis causes paracoccidioidomycosis (PCM) that is one of the most prevalent systemic human mycoses in Latin America. Armadillos show a high incidence of PCM infection and could, therefore, be a natural reservoir for this fungus. In this study were compared the virulence profiles of isolates obtained from nine-banded armadillos (Dasypus novemcinctus) (PbT1 and PbT4) and isolates from PCM patients (Pb265 and Bt83). Pathogenicity was evaluated by fungal load and analysis of colony morphology. Immunity against the fungus was tested by delayed type hypersensitivity test (DTH) and antibody quantification by ELISA. The higher virulence of PbT1 and PbT4 was suggested by higher fungal load in spleen and lungs. Armadillo isolates and Bt83 presented a cotton-like surface contrasting with the cerebriform appearance of $\mathrm{Pb265}$. All isolates induced cellular and humoral immune responses in infected BALB/c mice. DTH reactions were similarly induced by the four isolates, however, a great variability was observed in specific antibody levels, being the highest ones induced by Bt83 and PbT4. The present work confirms that armadillos harbor $P$. brasiliensis, whose multiplication and induced immunity in experimentally infected mice are heterogeneous, resembling the behavior of isolates from human PCM. This study reinforces the possibility that armadillos play an important role in the biological cycle of this pathogen.
\end{abstract}

Key-Words: Paracoccidioides brasiliensis, armadillos, infection, BALB/c mice.

Paracoccidioides brasiliensis is the etiological agent of paracoccidioidomycosis (PCM), the most prevalent systemic mycosis in Latin America [1]. P. brasiliensis is a thermally dimorphic fungus, which grows at room temperature as mycelia or develops multiple budding yeast form in human or experimental hosts or when cultured in vitro at $35-37^{\circ} \mathrm{C}$ [2]. Epidemiological studies demonstrated that the majority of the subjects exposed to $P$. brasiliensis develop an asymptomatic infection, indicating that they are resistant hosts. Even though a variety of clinical manifestations can be associated with the disease, two predominant types are described: the acute/ subacute or juvenile form that affects mainly young subjects of both sexes and involves the mononuclear-phagocytic system and the chronic or adult form that affects mainly adult males, who frequently present pulmonary and/or mucocutaneous involvement [3].

Several evidences show that propagules of P. brasiliensis conidia are the infective form, however, the natural habitat of this fungus is not fully determined. A few reports demonstrated isolation of this fungus from environment (soil, plants and animals). In addition, some studies confirmed the isolation of P. brasiliensis from nine-banded armadillos (Dasypus novemcinctus) in endemic regions of PCM, suggesting that these animals could be an important primary natural reservoir of this fungus [4-6]. The virulence of $P$. brasiliensis isolates obtained from armadillos has been studied using both, hamster

Received on 19 August 2007; revised 21 January 2008.

Address for correspondence: Dr. Alexandrina Sartori, M.D., Ph.D. Departamento de Microbiologia e Imunologia, Instituto de Biociências, UNESP, Distrito de Rubião Júnior, s/n, Botucatu, SP. Zip code CEP: 18618-000. Phone: 55 (14) 3811-6240; Fax: (14) 3815-3747. Email: sartori@ibb.unesp.br.

The Brazilian Journal of Infectious Diseases 2008;12(1):57-62. (C) 2008 by The Brazilian Journal of Infectious Diseases and Contexto Publishing. All rights reserved.
[7-9] and mouse virulence model systems [10]. These animal models have been extremely valuable to understand many aspects of protective immunity, histopathological alterations and also the host-parasite interaction in this fungal disease $[11,12]$. Moreover, these studies have also revealed different virulence profiles of $P$. brasiliensis isolates, which could explain the distinct clinical forms of the disease [13,14].

Similarities between fungal isolates from armadillo and clinical isolates have been shown in morphological, antigenic and molecular studies $[10,15,16]$. However, the real contribution of armadillos to the ecology and pathogenicity of P. brasiliensis isolates and to epidemiology of human PCM remains still unsolved.

Identification of antigenic components of $P$. brasiliensis that are able to induce specific immune response has provided useful tools for clinical diagnosis and for better understanding the outcome of the disease [17]. Immunity against $P$. brasiliensis is not completely understood, but many studies showed a strong correlation between high antibody levels and severity of the disease $[18,19]$. On the other hand, the cellular immune response characterized by persistent delayedtype hypersensitivity (DTH) and by macrophage activation through interferon-gamma and tumour necrosis factor-alpha, has been linked to resistance of human and animal hosts to infection $[20,21]$.

In this context, the aim of the present work was to compare the virulence profile of two isolates from armadillos (PbT1 and $\mathrm{PbT} 4)$ with two clinical isolates $(\mathrm{Pb} 265$ and $\mathrm{Bt} 83)$ and also to evaluate the cellular and humoral immune responses induced by these isolates in $\mathrm{BALB} / \mathrm{c}$ mice.

\section{Material and Methods \\ Animals}

Four to six-week-old male BALB/c mice were used. Animals were maintained at the Animal Facility of the Department of 
Microbiology and Immunology, São Paulo State University (UNESP), Botucatu, Brazil, supplied with filtered water and conventionally fed (Nuvital-CR1) ad libitum. Room temperature was set at $22^{\circ} \mathrm{C}$ and lighting consisted of alternate $12 \mathrm{~h}$ light/dark cycles.

\section{Fungal Isolates and Inoculum Preparation}

Two $P$. brasiliensis isolates (PbT1 and PbT4) were originally obtained from armadillos living in an endemic area for PCM (Botucatu, SP), as described previously [5] and then maintained in the laboratory by weekly cultivation. Two human isolates ( $\mathrm{Pb} 265$ and $\mathrm{Bt} 83)$ were also included in this study aiming to a comparative analysis. Bt83 was isolated from the sputum of a patient from Clinical Hospital of the School of Medicine, São Paulo State University in 1994, and $\mathrm{Pb} 265$ was obtained from the fungal culture collection of the Department of Microbiology, University of São Paulo, Brazil, and has been maintained in culture for more than 30 years, with no record of the precise date of isolation. P. brasiliensis isolates $\mathrm{Pb} 265$ and Bt83, respectively, are slightly and highly virulent for mice $[10,14,22]$. For inoculum preparation, the yeast form of the four isolates were grown in semi-solid medium containing $2 \%$ glucose, $1 \%$ peptone, $0.5 \%$ yeast extract and $2 \%$ agar (GPY) at $36^{\circ} \mathrm{C}$ for six days. Yeast cell suspensions were washed in phosphate buffered saline (PBS), pH 7.2 and viability was determined by phase contrast microscopy [23]. After being homogenized and agitated in a vortex for 5-10s, the suspensions were adjusted to $25.10^{6}$ viable yeasts $/ \mathrm{mL}$. Mice were infected with $5.10^{6} / 0.2 \mathrm{~mL}$ by intraperitoneal route. Fungal suspensions containing more than $90 \%$ viable cells were used for the experiments.

\section{Colony Morphology}

Colony morphology of the four isolates was evaluated by observation of giant colonies in their mycelial form, as described by Sano et al. [24]. Each isolate obtained from a six day-old culture in GPY medium at $35^{\circ} \mathrm{C}$ was plated on the central area of three 220x100 mm Petri dishes with Potato Dextrose Agar (PDA) with a platinum loop that allows an inoculation area of $3 \mathrm{~mm}$ in diameter. After 40 days of incubation at $25-28^{\circ} \mathrm{C}$, the colonies were examined for shape, size, texture and pigment production.

\section{Quantification of Colony Forming Units (CFU)}

Virulence was quantified by counting the number of viable fungi recovered from tissues of infected mice. Thirty and ninety days after infection, spleen and lungs were aseptically removed, weighed and individually homogenized in $2 \mathrm{~mL}$ of sterile PBS. Aliquots of 100 PL of each homogenate were plated by triplicate onto Petri dishes, with brain heart infusion (BHI) agar (Difco Laboratories, Detroit, Mich.) supplemented with $4 \%$ normal horse serum and 5\% $\mathrm{Pb} 192$ culture filtrate as a source of growthpromoting factor [25]. Plates were incubated at $35^{\circ} \mathrm{C}$ for three weeks and colonies were counted. The results were expressed as logarithmic values of the CFU counts per $g$ of tissue.

\section{Cell-Free Antigen Preparation}

Cell-free antigen (CFag) was obtained by the methodology described by Camargo et al. [26]. Briefly, Pb265 was grown in GPY medium at $35^{\circ} \mathrm{C}$ during four days. The fungal growth (about $300 \mathrm{mg}$ ) was collected by gently scraping the agarose surface. The cell mass was then resuspended in $1 \mathrm{~mL}$ of PBS, mixed for $30 \mathrm{~s}$ on a vortex-mixer and immediately centrifuged at $10,000 \mathrm{~g}$ during $1 \mathrm{~min}$. The supernatant was sterilized by filtration through a $0.22 \mathrm{Pm}$ membrane. Protein concentration was determined by the method of Lowry et al. [27]. Aliquots were kept at $-20^{\circ} \mathrm{C}$ until use but storage did not exceeded 15 days. The same procedure was used to obtain CFag from the other isolates, however, pilot experiments with the autologous CFag to evaluate antibody levels showed only basal levels of specific antibodies. Therefore, $\mathrm{CFag}$ from $\mathrm{Pb} 265$ was used as the antigen to evaluate humoral and also cellular immunity.

\section{Delayed Type Hypersensitivity Test}

The delayed type hypersensitivity (DTH) reaction was evaluated by the footpad swelling test as described previously [28]. Briefly, healthy or infected mice were inoculated, in one of the back footpads, with $50 \mathrm{Pg} / 50 \mathrm{PL}$ of CFag from Pb265. The footpad thickness was measured immediately before and 24 hours after antigen inoculation using a dial caliper (Mitutoyo, Tokyo, Japan) and was expressed in mm. Optimal antigen concentration for DTH assays was determined in preliminary experiments (not shown).

\section{Humoral Immunity}

Specific antibody levels to $P$. brasiliensis were evaluated by indirect enzyme-linked immunosorbent assay (ELISA) in blood samples collected after 15,30 and 70 days of infection. Plastic 96-well microtitration plates (MaxiSorp, Nunc, International Corp., Rochester, NY, USA) were coated with cell-free antigen prepared from $\mathrm{Pb} 265$ previously diluted in 0.05 M carbonate-bicarbonate buffer, $\mathrm{pH} 9.6(40 \mathrm{Pg} / \mathrm{mL})$ and incubated for $60 \mathrm{~min}$ at $37^{\circ} \mathrm{C}$ followed by an overnight incubation at $4^{\circ} \mathrm{C}$. The plates were washed with PBS containing $0.05 \%$ of Tween 20 (PBS/T). The remaining binding sites were blocked by addition of $5 \%$ non fat dry milk diluted in PBS/T during $30 \mathrm{~min}$ at $37^{\circ} \mathrm{C}$. Serum samples in two-fold dilutions were added after plate washing, and after $60 \mathrm{~min}$ incubation at $37^{\circ} \mathrm{C}$, the plates were washed again and a goat anti-mouse total immunoglobulin peroxidase conjugate (Sigma Chemical Co., St Louis, Mo, USA) diluted to 1/5,000 was added. After an additional incubation at $37^{\circ} \mathrm{C}$ for $60 \mathrm{~min}$, the plates were washed and covered with a mixture containing $o$ phenylenediamine $\left(10 \mathrm{mg}\right.$ ) plus $30 \mathrm{PL}$ of $30 \% \mathrm{H}_{2} \mathrm{O}_{2}$ diluted in $12.5 \mathrm{~mL}$ of citrate-phosphate buffer. Optical densities (OD) were read in an ELISA reader (Multiskan EX, Manchester, $\mathrm{UK}$ ) after reaction interruption with $4 \mathrm{~N} \mathrm{H}_{2} \mathrm{SO}_{4}$. A cut-off value was obtained by using 1:2 diluted sera from non-infected mice housed under identical conditions as the infected animals. Antibody titers were expressed as the reciprocal of the highest dilution whose OD was higher than the cut-off value. 


\section{Statistical Analysis}

The number of CFU/g of tissue, DTH reactions and antibody titers were analyzed by one-way analysis of variance (ANOVA) followed by multiple comparisons by the Tukey test. A p value of $<0.05$ was considered significant.

\section{Results}

High Fungal Loads are Recovered from Mice Infected with $P$. brasiliensis Isolated from Armadillos

Thirty and 90 days after infection by intraperitoneal route, mice were sacrificed and the fungal load determined by the number of CFU in spleen and lungs. As can be observed in Figure $1 \mathrm{a}$ for the lungs and Figure $1 \mathrm{~b}$ for the spleen, higher amounts of fungal cells were recovered from animals infected with $\mathrm{PbT} 1$ and PbT4 in comparison to the clinical isolates. The number of CFU detected in lungs of mice infected with $\mathrm{PbT} 1$ was significantly higher in relation to the animals inoculated with $\mathrm{Pb} 265$ at 30 and 90 days of infection. CFU recovered from the spleen of the animals infected with $\mathrm{PbT} 1$ and PbT4 at 30 and 90 days of infection were significantly higher than those obtained from mice inoculated with $\mathrm{Pb} 265$ at the same periods and higher than in animals inoculated with Bt83 at 30 days of infection. Interestingly, at 90 days of infection the fungi disappeared from lungs in animals infected with $\mathrm{PbT} 4$, but these animals still presented high amounts of fungi in their spleens.

\section{$\underline{\text { P. brasiliensis Isolated from Armadillos Develop a Cottony }}$ Phenotype}

Phenotypes of $P$. brasiliensis isolates were distinguished mainly by differences in colony size, shape, texture and pigment production. Both $\mathrm{Pb}$ isolates from armadillos developed larger colonies than the clinical isolates. They presented a typical cotton-like surface that varied in color from white to beige. Also, a central fissure was observed in PbT4 (Figure 2a) but not PbT1 (Figure 2b). Bt83 morphology was more similar to armadillo isolates. In this case, the colony presented an intense wrinkled appearance and a predominant white cotton-like surface (Figure 2c). Also, a very pronounced central fissure was observed presenting a brownish color. On the other hand, $\mathrm{Pb} 265$ presented a very distinct glabrous phenotype characterized by an irregular format and a cerebriform surface (Figure 2d).

\section{$\underline{P .}$ brasiliensis Isolated from Armadillos Induce Cellular $\underline{\text { Immunity in Mice }}$}

Cellular immunity evaluated by delayed-type hypersensitivity (DTH) test was similarly induced by the four isolates and was characterized by a significant increase in the footpad thickness in comparison to non-infected controls, as depicted in Figure 3. As can be observed, some variation was associated with the different isolates. The higher increases in the footpad thickness were detected in animals infected with $\mathrm{Pb} 265$, the highest value being found at the $70^{\text {th }}$ day of infection. The DTH reactions found in mice infected with $\mathrm{Bt} 83, \mathrm{PbT} 1$ and PbT4 were similar in intensity, except at the $70^{\text {th }}$ day of infection when the footpad increase was not significant in the group infected with PbT4.

\section{P. brasiliensis from Armadillos Induce Humoral Immunity in Mice}

All four isolates were able to induce specific antibody production after intraperitoneal infection in $\mathrm{BALB} / \mathrm{c}$ mice when the sera were tested with CFag obtained from $\mathrm{Pb} 265$ (Figure 4). Antibody levels detected by using the homologous CFag (Bt83, PbT1 and PbT4) were very low and similar to basal levels found in non-infected mice (not shown). All $\mathrm{Pb}$ isolates induced lower antibody levels at 15 than at 30 and 70 days after infection. Antibody levels induced by Pb265, PbT1 and $\mathrm{PbT} 4$ were similar at 30 and 70 days after infection, with no statistical difference among them. Only the Bt83 isolate elicited a very distinct serological profile characterized by a significantly higher antibody titer in comparison to the three other isolates.

\section{Discussion}

In this study we evaluated the ability of $P$. brasiliensis isolated from armadillos to cause disease in mice and we also studied their ability to induce immune response in this experimental model. These characteristics were also compared to the ones of clinical P. brasiliensis isolates. Mice were chosen as animal models because they have been very useful to study host-parasite interactions in PCM. This model indicated that distinct $P$. brasiliensis isolates vary in their virulence, which could explain the diversity found in clinical manifestations of this disease [13, 29, 30].

Two parameters of virulence were analyzed: amounts of fungi in spleen and lungs and the morphology of giant colonies from the fungal mycelial form. Higher fungal loads were recovered from mice infected with armadillo isolates in comparison with the two clinical isolates, $\mathrm{Bt} 83$ and $\mathrm{Pb} 265$, suggesting, therefore, that armadillo isolates were more virulent. According to Singer-Vermes et al. [19], estimation of the number of viable fungi in infected mouse organs by CFUs counts is one of the most direct and trustworthy methods to assess severity of this disease. The results observed in mice infected with Bt83 differed from those previously reported, i.e., we expected the recovery of higher amounts of fungi in this case. Lower fungal loads of Bt83 isolate obtained from organs of infected mice could be attributed to the phenomenon known as virulence attenuation that has been described for $P$. brasiliensis $[9,24]$ and also for other fungi that cause deep mycosis, such as Blastomyces dermatitidis [31] and Cryptococcus neoformans [32]. Spleen colonization was similar between the two armadillo $\mathrm{Pb}$ isolates, however, at 90 days, more fungi were recovered from the lung tissue in $\mathrm{PbT} 1$ infected mice. It is tempting to speculate that this isolate has a higher tropism or ability to disseminate to lungs than $\mathrm{PbT} 4$. Some support to this hypothesis is given by the finding of Singer-Vermes et al. [14] that showed that distinct $P$. 
Figure 1. Fungi recovery (CFU) from mice infected with $P$. brasiliensis isolates. Lungs (A) and spleens (B) were collected from infected mice after 30 and 90 days of infection $\left(5.10^{6}\right.$ yeasts $/ 0.2 \mathrm{~mL} / \mathrm{i} . \mathrm{p}$. route) and the number of CFU was determined by plating in BHI media enriched with horse serum and fungi growth factor. Each bar represents the mean $+/$ - SEM CFU per gram of the tissue from six animals.

A

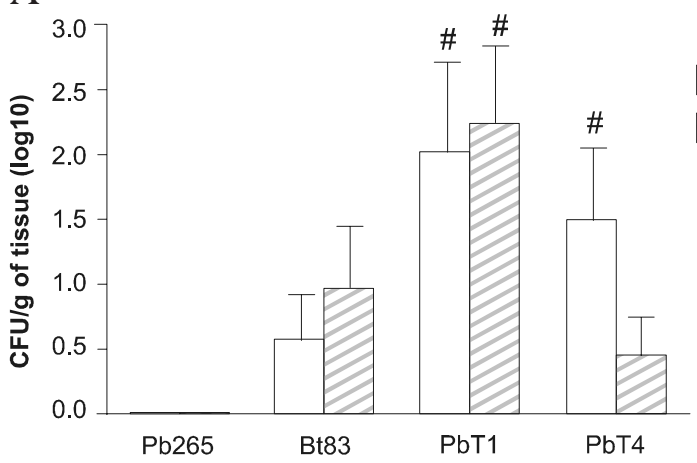

B

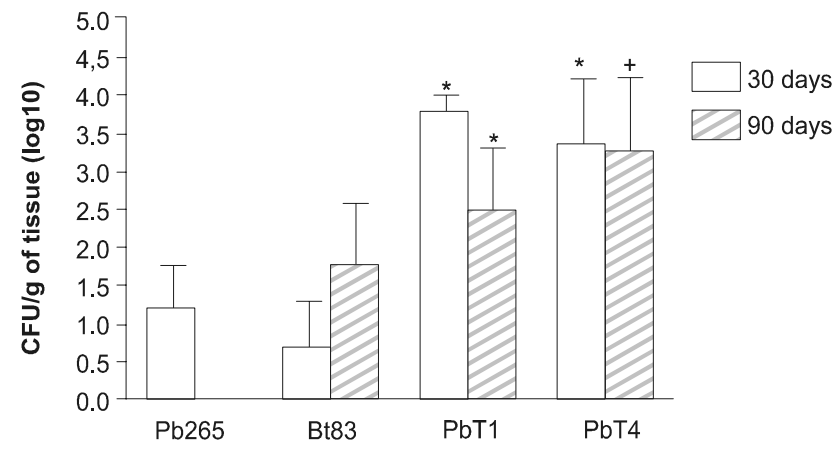

\# ( $\mathrm{p}<0.05)$ versus $\mathrm{Pb} 265$ (30 and 90 days); * ( $<<0.05)$ versus $\mathrm{Pb} 265$, Bt83 (30 days); + ( $<<0.05)$ versus $\mathrm{Pb} 265$ (90 days).

Figure 2. Colony morphology: comparison among the four isolates. Giant colonies from Paracoccidioides brasiliensis isolates, cultured at $25^{\circ} \mathrm{C}$ on potato dextrose agar medium. a) PbT4; b) PbT1; c) Bt83; d) Pb265.

a

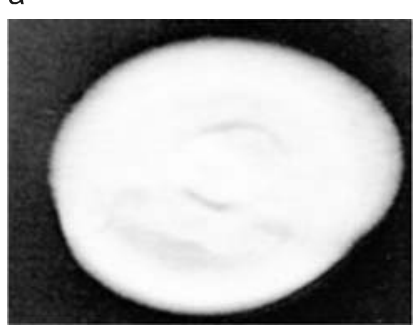

b

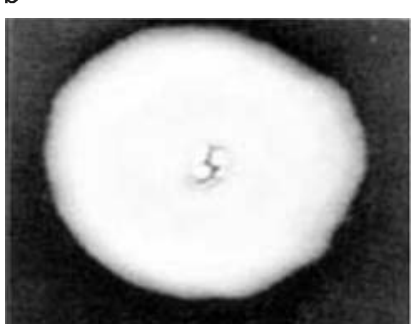

C

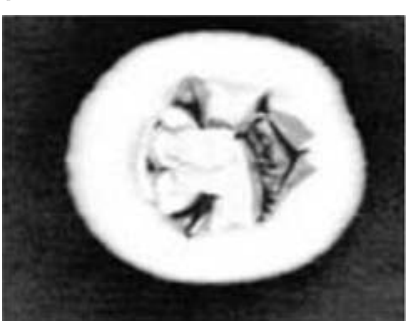

d

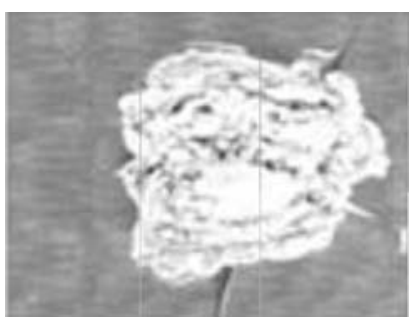

Figure 3. Delayed type hypersensitivity (DTH) reactions in mice infected with Paracoccidioides brasiliensis isolates. Results are expressed as mean +/- SEM of footpad swelling obtained from five animals per period of infection. BALB/c male mice were infected by intraperitoneal route with $5.10^{6}$ yeasts/0.2 $\mathrm{mL}$ and then $(15,30$ and 70 days after infection) they were challenged with $50 \mathrm{Pg} / 50 \mathrm{PL}$ of $P$. brasiliensis 265 CFAg in the footpad. Twenty-four hours later the increase of the footpads was measured by using a caliper.

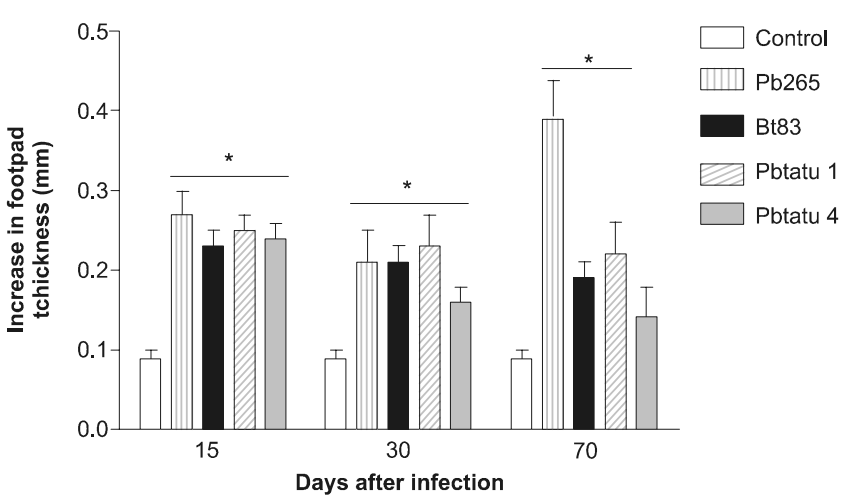

$*(p<0.05)$ versus control.
Figure 4. Specific antibodies in mice infected with Paracoccidioides brasiliensis isolates. BALB/c male mice were infected by intraperitoneal route with $5.10^{6}$ yeasts $/ 0.2$ $\mathrm{mL}$ and then $(15,30$ and 70 days after infection) they were sacrificed and serum samples were obtained by retro-orbital puncture. Results are expressed as mean +/- SEM of the highest reciprocal serum dilution from six animals.

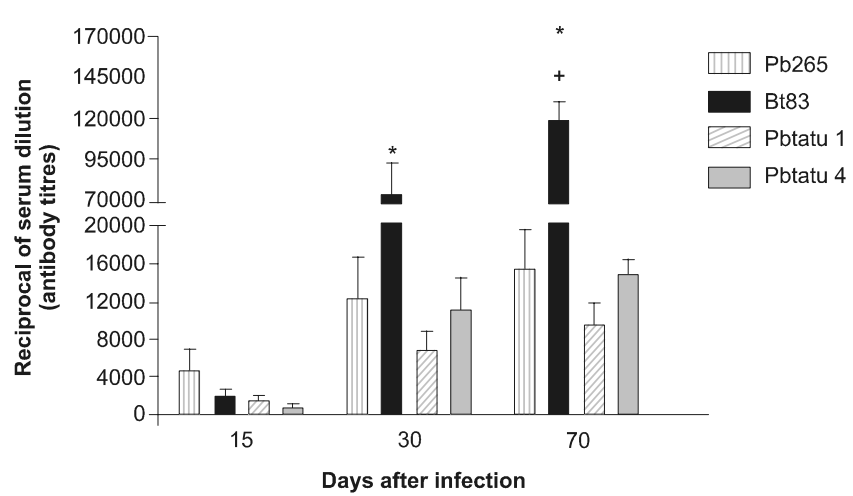

( $\mathrm{p}<0.05)$ versus 15 days; $+(\mathrm{p}<0.05)$ versus $\mathrm{Pb} 265, \mathrm{PbT} 1, \mathrm{PbT} 4$ (70 days). 
brasiliensis strains showed ability to colonize distinct organs and tissues.

The morphological characteristics of the giant colonies were also evaluated and compared. Both isolates from armadillos presented a very similar appearance: they were rounded showing a white cotton-like surface. The Bt83 colony was similar, being also rounded and showing a predominant white cotton-like surface. As the isolates from armadillos were recovered in higher amounts from infected mice than Bt83, our results are in accordance with previous reports. Kurokawa et al. [10] and Sano et al. [24] showed that P. brasiliensis isolates with low in vitro subculture time and cottony morphology frequently present higher virulence, while isolates with cottony phenotype, but longer in vitro subculture period present lower or intermediate virulence. It is well known that long in vitro subculture period of isolates are associated with virulence attenuation $[7,29]$. Thus, as expected, $\mathrm{Pb} 265$ colony presented a very distinctive appearance, being glabrous and characterized by an irregular format and a beige cerebriform surface. These characteristics are in accordance with its low dissemination; only a few colonies were detected in the spleen after 30 days of infection and no fungi were found in the lungs.

Specific antibodies are not protective in PCM, however, its measurement is useful for monitoring the progress of the disease in patients [33]. In this context, higher antibody levels were expected in mice infected with $\mathrm{PbT} 1$ and $\mathrm{PbT} 4$, due to the higher dissemination observed in organs of these infected mice. However, the highest antibody levels were only detected throughout the infection with Bt83. On the other hand, both armadillo isolates were able to induce significant antibody levels, similarly to the one induced by $\mathrm{Pb} 265$. One of the possible explanations for these seemingly unexpected results could be the origin of the antigen used for ELISA. Initially, cell-free antigen from each isolate was used in ELISA. However, only very low antibody titers were detected. Since the use of cell-free antigen from $\mathrm{Pb} 265$ detected much higher antibody levels, this antigen source was chosen for antibody and DTH evaluation. Cellular immunity has been described as the most important defense against $P$. brasiliensis. Macrophages activated by cytokines produced by itself and derived from $\mathrm{T}$ helper 1 cells are fundamental to eliminate the fungi [20,21]. In this scenario, a differential cellular immunity was expected in mice infected with the four isolates. However, by using a DTH assay, we observed that all four isolates were able to induce a significant increase in the footpad thickness.

Some general comments could be derived from this data. First of all, PbT1 and PbT4 showed some characteristics that are commonly found in the originally more virulent strains including higher multiplication in the murine host and also the cottony colony morphology. On the other hand, their ability to induce antibody production seemed more similar to $\mathrm{Pb} 265$ that determines a much milder disease in mice. In addition, all four isolates were able to induce cellular immunity in mice experimentally infected.
Variation in the virulence pattern of $P$. brasiliensis isolated from armadillos was previously reported in hamster and mouse models of PCM and a comparative analysis was done with the clinical isolates. The armadillo P. brasiliensis isolates were classified as highly to intermediately virulent to hamsters and lowly virulent to mouse in comparison to clinical isolates $[7,8,10]$. These findings suggest that $P$. brasiliensis samples obtained from armadillos presented a heterogeneous behavior, being difficult to define then as virulent or not. However, this complex behavior is similarly observed in isolates obtained from human PCM. Thus, the data demonstrated in the present work reinforce the possibility that armadillos play an important role in the biological cycle of this fungal pathogen, acting as a natural reservoir of $P$. brasiliensis isolates, which could be able to infect and cause disease in human and animal hosts. The data also agree with some previous molecular and virulence studies indicating that armadillos isolates can encompass a significant biodiversity, that might reflect the different patterns of host-pathogen interactions $[8,34]$. It was already suggested that armadillos, by having a constant contact with soil in habitats supporting $P$. brasiliensis, in combination with its low body temperature and a weak cellmediated immunity, could be infected by and disseminate a wider genotype spectrum of the pathogen than that found in clinical isolates.

\section{Acknowledgement}

We are thankful to Fundação de Amparo à Pesquisa do Estado de São Paulo (FAPESP), for the fellowship (97/104461) to Angela Nishikaku.

\section{References}

1. Wanke B., Londero A.T. Epidemiology and paracoccidioidomycosis infection. In: Franco M.F., Lacaz C.S., Restrepo A., Del Negro G. eds. Paracoccidioidomycosis. Boca Raton, FL., CRC Press, 1994.

2. McEwen J.G., Bedoya V., Patiño M.M., et al. Experimental murine paracoccidioidomycosis induced by the inhalation of conidia. $\mathrm{J}$ Med Vet Mycol 1987;25:165-75.

3. Brummer E., Castañeda E., Restrepo A. Paracoccidioidomycosis: an update. Clin Microbiol Rev 1993;6:89-117.

4. Naiff R.D., Ferreira L.G.L., Barret T.V., et al. Paracoccidioidomicose enzoótica em tatus (Dasypus novemcinctus), no Estado do Pará. Rev Inst Med Trop São Paulo 1986;28:19-27.

5. Bagagli E., Sano A., Coelho K.I.R., et al. Isolation of Paracoccidioides brasiliensis from armadillos (Dasypus novemcinctus) captured in an endemic area of paracoccidioidomycosis. Am J Trop Med Hyg 1998;58:505-12.

6. Corredor G.G., Castaño J.H., Peralta L.A., et al. Isolation of Paracoccidioides brasiliensis from the nine-banded-armadillo Dasypus novemcinctus, in an endemic area for paracoccidioidomycosis in Colombia. Rev. Iberoam. Micol 1999; $16: 216-20$

7. Peraçoli M.T.S., Sugizaki M.F., Mendes R.P., et al. Paracoccidioides brasiliensis isolated from armadillos is virulent to Syrian hamsters. Mycopathologia (Den Haag) 1999;148:123-30.

8. Hebeler-Barbosa F., Montenegro M.R., Bagagli E. Virulence profiles of ten Paracoccidioides brasiliensis isolates obtained from armadillos (Dasypus novemcinctus). Med Mycol 2003a; $41: 89-96$. 
9. Macoris S.A.G., Sugizaki M.F., Peraçoli, M.T.S., et al. Virulence attenuation and phenotypic variation of Paracoccidioides brasiliensis isolates obtained from armadillos and patients. Mem Inst Oswaldo Cruz 2006; 101:331-4.

10. Kurokawa C.S., Lopes C.R., Sugizaki M.F., et al. Virulence of profile of ten Paracoccidioides brasiliensis isolates. Association with morphologic and genetic patterns. Rev Inst Med Trop S Paulo 2005;47:257-62.

11. Calich V.L.G., Singer-Vermes L.M., Russo M., et al. Immunogenetics in Paracoccidioidomycosis. In: Franco M.F., Lacaz C.S., Restrepo A., Del Negro G. eds. Paracoccidioidomycosis. Boca Raton, FL., CRC Press, 1994.

12. Coelho K.I., Defaveri J., Rezkallah-Iwasso M.T., Peraçoli M.T.S. Experimental paracoccidioidomycosis. In: Franco M.F., Lacaz C.S., Restrepo A., Del Negro G. eds. Paracoccidioidomycosis. Boca Raton, Fla., CRC Press, 1994.

13. Kashino S.S., Calich V.L.G., Burger E., Singer-Vermes L.M. In vivo and in vitro characteristics of six Paracoccidioides brasiliensis strains. Mycopathologia (Den Haag) 1985;92:173-8.

14. Singer-Vermes L.M., Burger E., Franco M.F., et al. Evaluation of the pathogenicity and immunogenicity of seven Paracoccidioides brasiliensis isolates in susceptible inbred mice. J Med Vet Mycol 1989;27:71-82.

15. Vidal M.S., De Melo N.T., Garcia N.M., et al. Paracoccidioides brasiliensis. A mycological and immunochemical study of a sample isolate from an armadillo (Dasypus novemcinctus). Rev Inst Med Trop Sao Paulo 1995; 37:43-9.

16. Sano A., Tanaka R., Yokoyama K., et al. Comparison between human and armadillo Paracoccidioides brasiliensis isolates by random amplified polymorphic DNA analysis. Mycopathologia (Den Haag) 1999;143:165-9.

17. Camargo Z.P., Franco M.F. Current knowledge on pathogenesis and immunodiagnosis of paracoccidioidomycosis. Rev Iberoam Micol 2000; $17: 41-48$.

18. Biagioni L., Souza M.J., Chamma L.G., et al. Serology of paracoccidioidomycosis. II. Correlation between class-specific antibodies and clinical forms of the disease. Trans R Soc Trop Med Hyg 1984;78:617-21.

19. Singer-Vermes L.M., Caldeira C.B., Burger E., Calich V.L.G., Experimental murine paracoccidioidomycosis: relationship among the dissemination of the infection, humoral and cellular immune responses. Clin Exp Immunol 1993;94:75-9.

20. Moscardi-Bacchi M., Brummer E., Stevens D.A. Support of Paracoccidioides brasiliensis multiplication by human monocytes or macrophages: inibition by activated phagocytes. J Med Microbiol 1994;40:159-64.

21. Calich V.L.G., Vaz C.A.C., Burger E. Immunity to Paracoccidioides brasiliensis infection. Res Immunol 1998;149:407-17.
22. Zacharias D., Ueda A., Moscardi-Bacchi M., Franco M., San-Blás G. A comparative histopathological, immunological and biochemical study of experimental intravenous paracoccidiodomycosis induced in mice by three Paracoccidioides brasiliensis isolates. J Med Vet Mycol 1986; $24: 445-54$

23. Soares A.M.V.C., Calvi S.A., Peraçoli M.T.S., et al. Modulatory effect of prostaglandins on human monocyte activation for killing of high- and low- virulence strains of Paracoccidioides brasiliensis. Immunol 2001;102:480-5.

24. Sano A., Tanaka R., Nishimura K., et al. Characteristics of 17 Paracoccidioides brasiliensis isolates. Mycoscience 1997;38:117-22.

25. Singer-Vermes L.M., Ciavaglia M.C., Kashino S.S., et al. The source of the growth-promoting factor(s) affects the plating efficiency of Paracoccidioides brasiliensis. J Med Vet Mycol 1992;30:261-4.

26. Camargo Z.P., Taborda C.P., Rodrigues E.G., Travassos L.R. The use of cell-free antigens of Paracoccidioides brasiliensis in serological tests. J Med Vet Mycol 1991;29:31-8.

27. Lowry O.H., Rosembrough N.J., Farr A.L., Randall R.J. Protein measurement with the folin phenol reagent. J Biol Chem 1951; 193:265-75.

28. Fazioli R.A., Singer-Vermes L.M., Kashino S.S., et al. Delayedtype hypersensitivity response in an isogenic murine model of paracoccidioidomycosis. Mycopathologia (Den Haag) 1994; $126: 137-46$.

29. Brummer E., Restrepo A., Hanson L.H., Stevens D.A. Virulence of Paracoccidioides brasiliensis: the influence of in vitro passage and storage. Mycopathologia (Den Haag) 1990;109:13-7.

30. Singer-Vermes L.M., Burger E., Calich V.L.G., et al. Pathogenicity and immugenicity of Paracoccidioides brasiliensis in the human disease and in an experimental murine model. Clin Exp Immunol 1994; 97:113-9.

31. Brass C., Volkmann C.M., Philpott D.E., et al. Spontaneous mutant of Blastomyces dermatitidis attenuated in virulence for mice. Sabouradia 1982;20:145-58.

32. Franzot S.P., Murkherjee J., Cherniak R., et al. Microevolution of a standard strain of Cryptococcus neoformans resulting in differences in virulence and other phenotypes. Infect Immun 1998; 66:89-97.

33. Fava-Netto $C$. The serology of paracoccidioidomycosis: present and future trends. Pan Am Health Organ 1972;254:209-13.

34. Hebeler-Barbosa F., Morais F.V., Montenegro M.R., et al. Comparison of the sequences of the internal transcribed spacer regions and Pbgp43 genes of Paracoccidioides brasiliensis from patients and armadillos (Dasypus novemcinctus). J Clin Microbiol 2003b;41:5735-7. 